This issue of Psyche is dedicated to the memory of Joseph C. Bequaert, who died in his 96th year in Amherst, Massachusetts, on January $12,1982$.

Dr. Bequaert was born in Belgium in 1886 and was educated there, receiving his Dr. Phil. degree in botany in 1908 from the State University in Ghent. The next seven years he spent in the Belgian Congo (now Zaïre), at first as Entomologist on the Belgian Sleeping Sickness Commission and later as head of botanical explorations in the Congo for the Belgian Colonial Government. During those years his main interest shifted from botany to entomology, in which he subsequently did the greater part of his research and teaching. In 1917 he was appointed Research Associate in Congo Zoology at the American Museum of Natural History. Six years later, after becoming a naturalized citizen of the United States, he joined the faculties of the Harvard School of Public Health and the Harvard Medical School, as an assistant professor in medical entomology, and remained there until 1945. He then accepted the position of Curator of Recent Insects in the Museum of Comparative Zoology, succeeding Nathan Banks. In 1951 he was appointed Alexander Agassiz Professor of Zoology, a chair that he held until his retirement in 1956. Most of the remaining 26 years of his life were spent in Tucson, Arizona, where he was associated with the departments of entomology and zoology at the University of Arizona.

He was internationally known for his publications, totalling more than 250 , on medical entomology, mollusks, botany, and systematics of several families of insects.

Joe joined the Cambridge Entomological Club in 1923, as soon as he reached the Boston area, and he was very active in the society for the next 33 years. He was president in 1928, 1935-36, and 1942-43; vice-president in 1937, 1941, and 1946; secretary in 1925 and 1926; and treasurer in 1943. He also served on the editorial board of Psyche from 1947-1956. He gave many of the scheduled talks at our regular meetings and was chosen as the speaker for the 500th meeting of the Club on December 15, 1931. In recognition of his services and contributions to the activities of the society, he was elected an Honorary Member in 1961. 


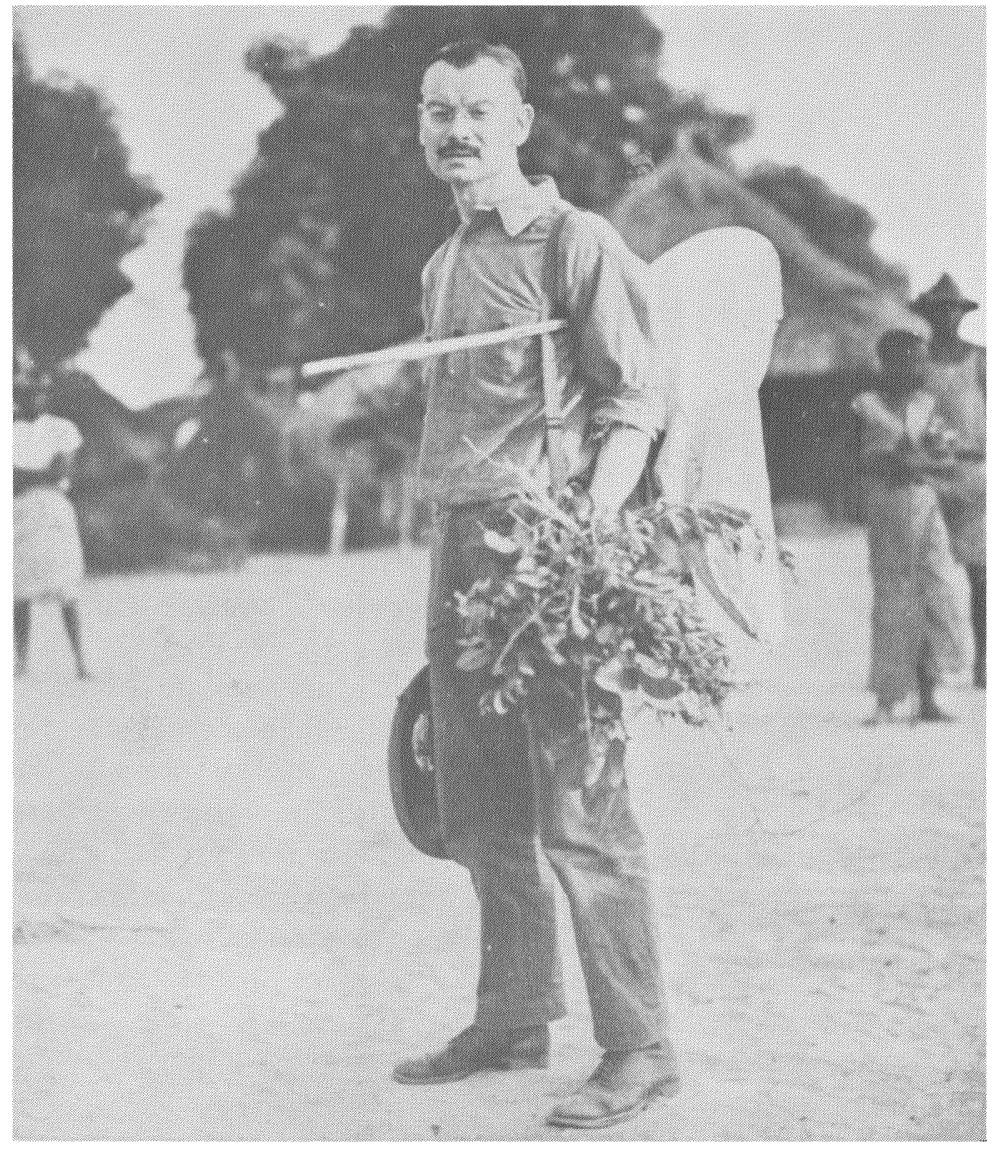

\section{Joseph Charles BequaerT}

Photograph taken in Belgian Congo, 1934

I first met Joe at the September meeting of the Club in 1923, at which he was nominated for membership. His exuberance and his extraordinary enthusiasm for nearly every aspect of natural history were the most obvious traits of his personality. In 1956 he wrote the following statement of his scientific interests: ecology of flowers; taxonomy and ecology of Bryophyta; geography and ecology of African plants; relations of Arthropoda to disease; taxonomy and ethology of Diptera and Hymenoptera, particularly Vespidae; malacology; medical entomology. He was certainly one of the most distinguished and respected entomologists of his generation.

Frank M. Carpenter, editor 

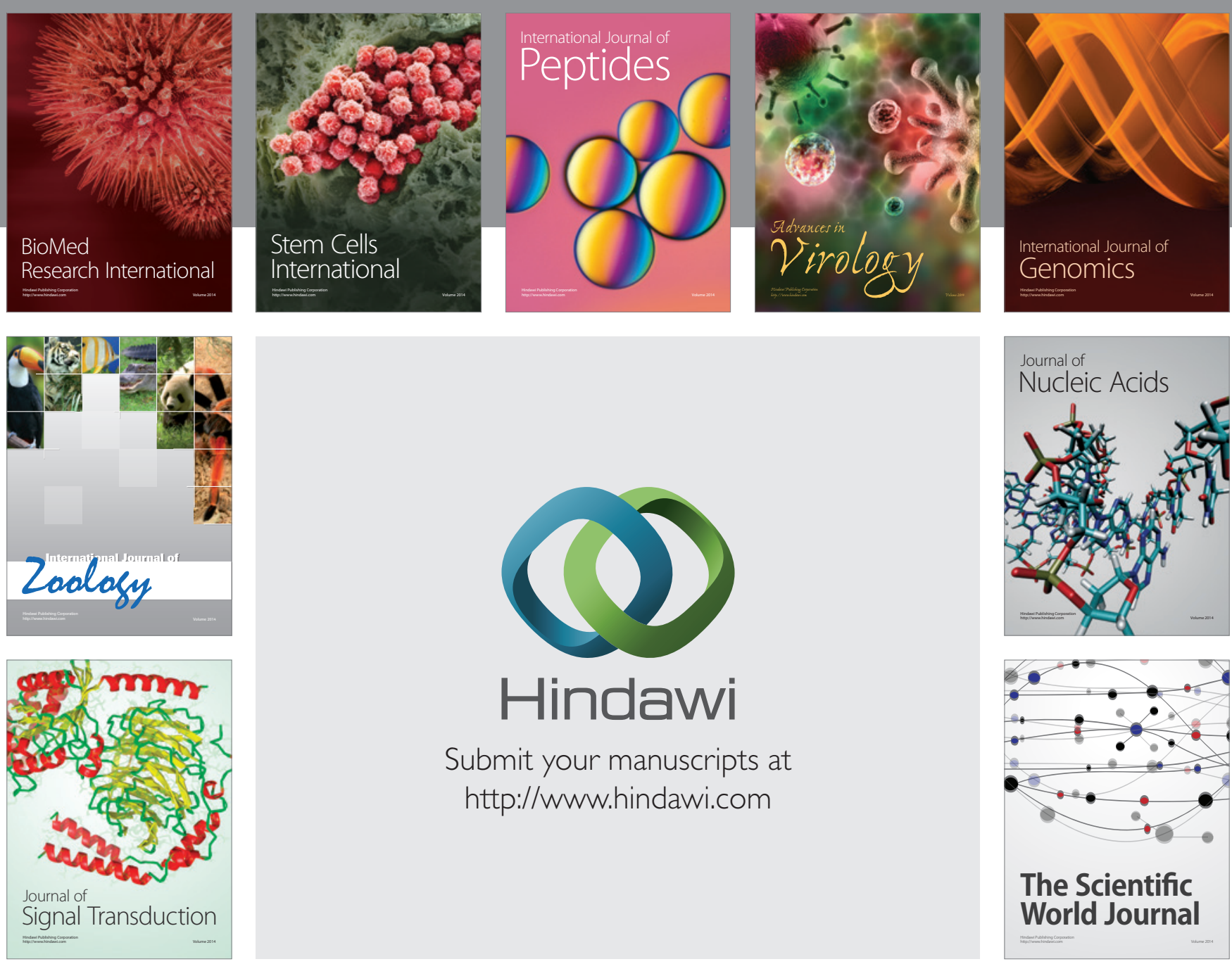

Submit your manuscripts at

http://www.hindawi.com
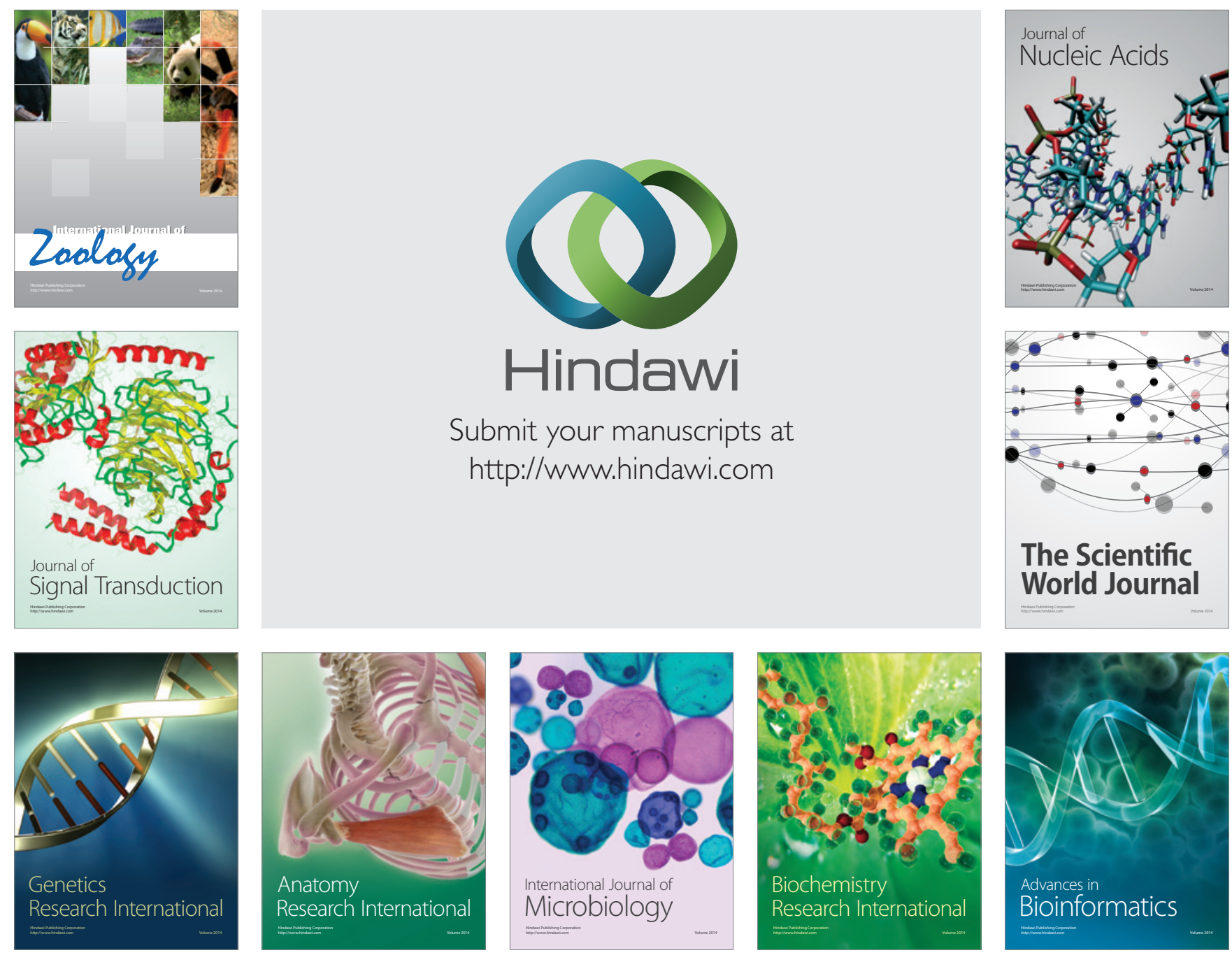

The Scientific World Journal
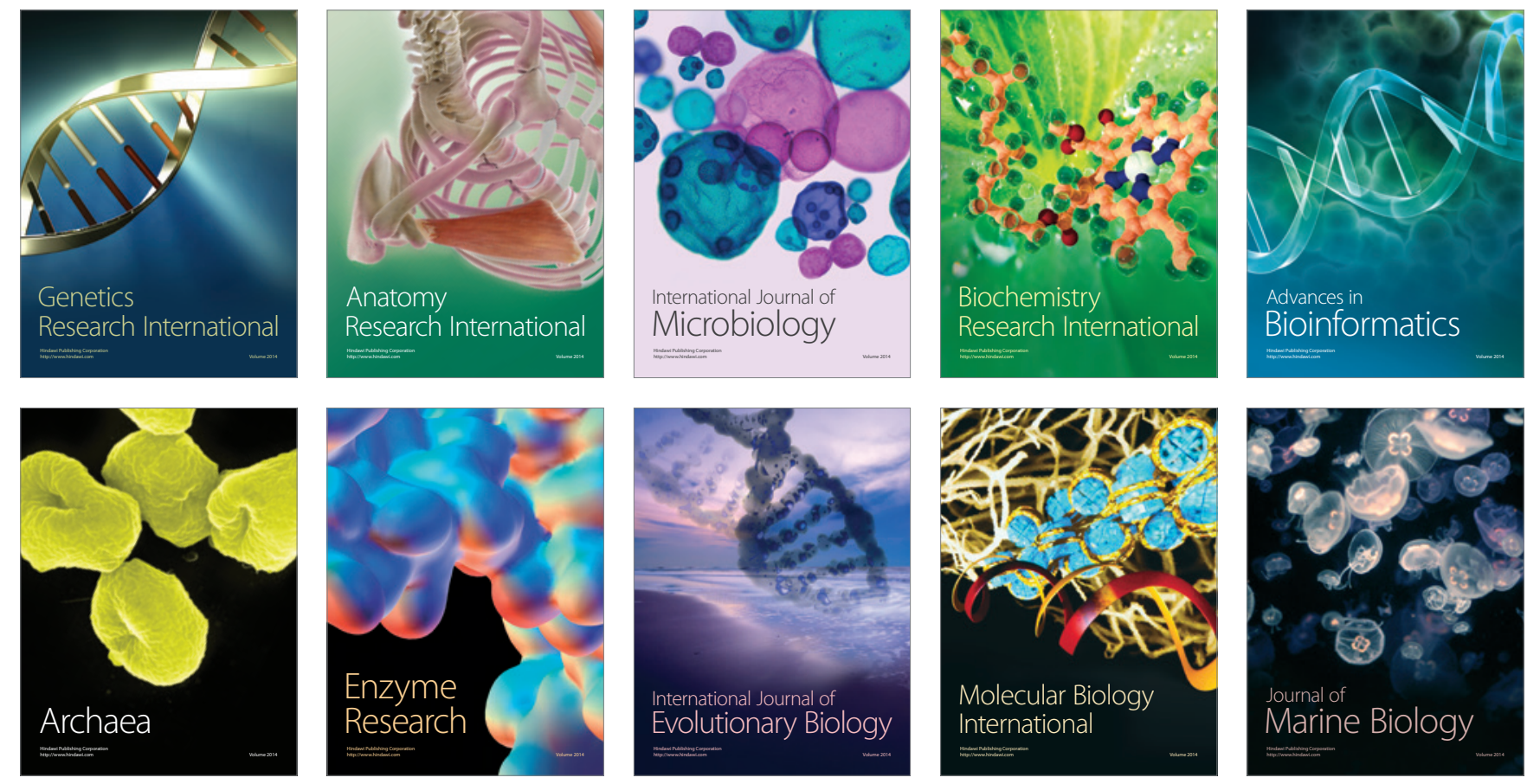